\title{
The new trend for search engine optimization, tools and techniques
}

\author{
Asim Shahzad ${ }^{1}$, Deden Witarsyah Jacob ${ }^{2}$, Nazri Mohd $\mathrm{Nawi}^{3}$, Hairulnizam Mahdin ${ }^{4}$, \\ Marheni Eka Saputri ${ }^{5}$ \\ 1,3,4,5Faculty of Computer Science and Information Technology, Universiti Tun Hussein Onn Malaysia, Malaysia \\ ${ }^{2,5}$ Department of Industrial Engineering, Telkom University, Indonesia
}

\begin{tabular}{l}
\hline Article Info \\
\hline Article history: \\
Received Oct 5, 2019 \\
Revised Dec 6, 2019 \\
Accepted Dec 20, 2019 \\
\hline
\end{tabular}

\section{Keywords:}

Search engine optimization

Search engines (SE)

SEO techniques

SEO tools

White hat SEO

\begin{abstract}
Search Engines are used to search any information on the internet. The primary objective of any website owner is to list their website at the top of all the results in Search Engine Results Pages (SERPs). Search Engine Optimization is the art of increasing visibility of a website in Search Engine Result Pages. This art of improving the visibility of website requires the tools and techniques; This paper is a comprehensive survey of how a Search Engine (SE) works, types and parts of Search Engine and different techniques and tools used for Search Engine Optimization (SEO.) In this paper, we will discuss the current tools and techniques in practice for Search Engine Optimization.
\end{abstract}

Copyright () 2020 Institute of Advanced Engineering and Science. All rights reserved.

\section{Corresponding Author:}

Hairulnizam Mahadin,

Faculty of Computer Science and Information Technology,

Universiti Tun Hussein Onn Malaysia,

Parit Raja, Johor Malaysia.

Email: hairuln@uthm.edu.my

\section{INTRODUCTION}

The internet is a popular global information system where users are searching for the relevant information using Search Engines (SE). The SE is a type of software that organizes the content collected from all across the internet [1]. With SE, users who are wishing to find information only need to enter a keyword about what they had like to see, and the search engine presents the links to the content that resembles what they need. The most popular and widely used SE on the internet is Google where 77 percent of users around the world are using Google Search Engine for searching information on the internet [1,2]. Other than that, there are some other very good Search Engines that are available on the internet. The other different top Search Engine includes Baidu, Bing, Yahoo, Ask and Dogpile [1]. Every web search engine aims to search and organize scattered data located on the internet. Before the development of any search engine, the internet was just a set of File Transfer Protocol (FTP) websites, where users were navigating to get specific shared files [3]. Over time more and more web servers were joining the internet so the need for organizing and searching the distributed data file on File Transfer Protocol (FTP) web servers increased [4]. So, the development of search engine started due to this requirement to navigate the FTP web servers and data on the Internet more easily and efficiently [3]. Figure 1 shows the complete history of search engines $[4,5]$. 


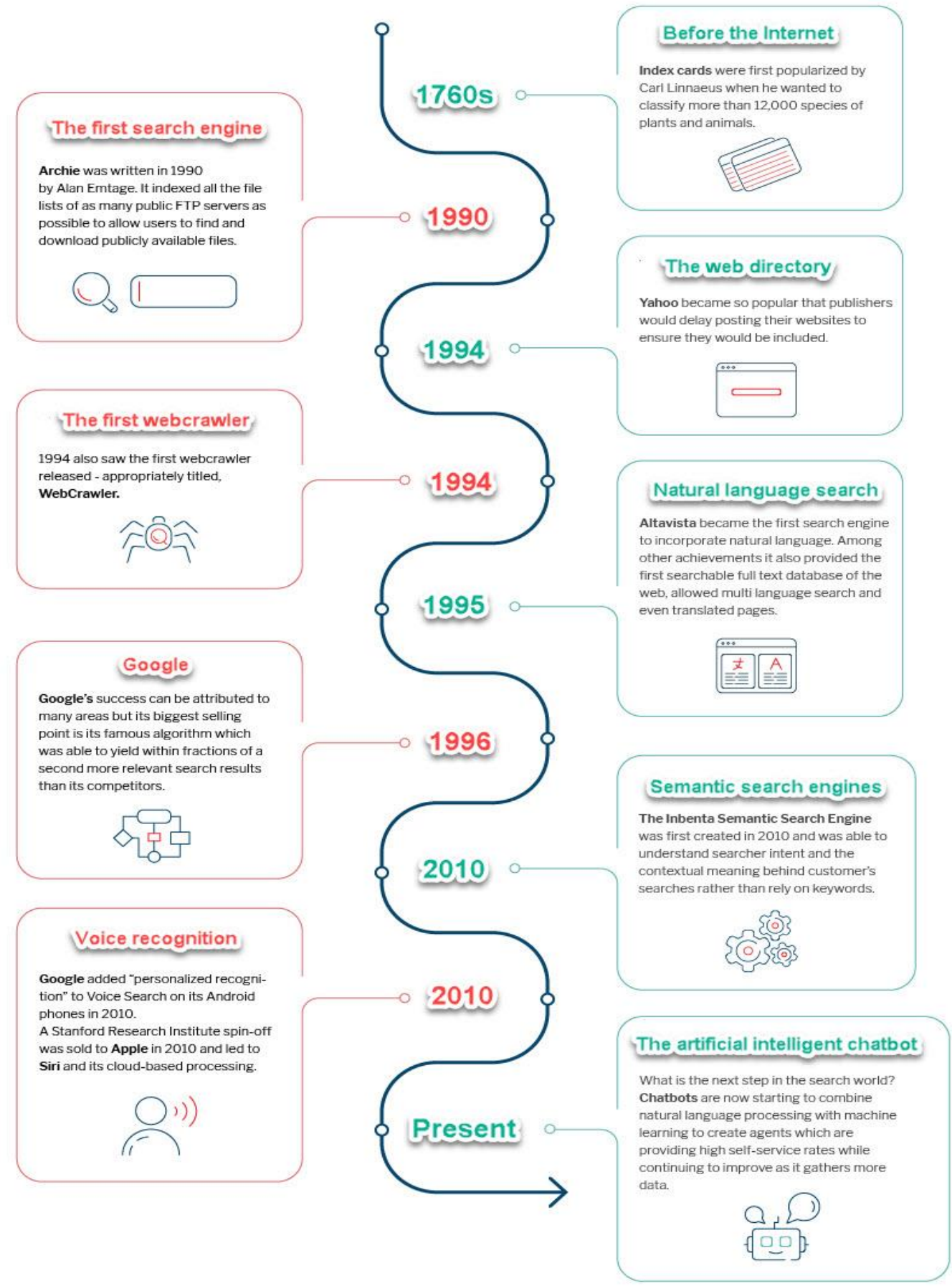

Figure 1. History of search engines

Every owner of website wants to display their sites on the top in Search Engine Result Pages and for that reason they prefer to use Search Engine Optimization techniques [6]. SEO is the technique of optimizing a complete website or few web pages to make them friendly for Search Engine Crawlers for obtaining the best possible rank in Search Engine Result Pages. Simply, the practice of improving the quality and quantity of organic traffic to any site is known as Search Engine Optimization [6, 7]. For better understanding about the SEO, it is necessary to know the quality and quantity of traffic and organic results.

Quality of traffic: SEO expert can bring a lot of visitors to a website, but if visitors are coming to the site just because of Google shows them website that display only for online movies while in reality site is selling cell phones, this is not considered as quality traffic. Instead, website wants to pull visitors who are genuinely interested in the products that site offers [8]. 
Quantity of traffic: Once a website is getting the right visitors (who are genuinely interested in websites' products) from Search Engine Results Pages, then SEO expert should work for more traffic. More traffic is better for website ranking [9].

Organic results: In most of SERPs the top three results are consist of advertisements. Owners of different websites are paying the Search Engines for showing their sites in top three results on SERPs [10]. The opposite of paid traffic is organic traffic. It is referring to the visitors that come to the site as a result of natural (unpaid) search results. Where those visitors who find a website using Search Engines like Bing, Google, Badu are considered as organic $[6,8,10]$. Moreover, there are some critical factors which can affect the SEO such as, how a website is designed and developed, knowledge of search algorithms that show how it works, research on user's keywords that what they might search, and wisely used on-page and off-page SEO techniques.

Therefore, this article aims to provide a brief survey on how search engines are working, what is SEO and what are the tools and techniques for SEO currently in use. The paper is divided into further 5 sections. Section 2 provides a review of how a search engine works, essential components and types of search engines. In Section 3 we will discuss types and techniques of Search Engine Optimization. Section 4 provides the details about Search engine optimization tools. In Section 5 we will discuss about Mobile vs. Desktop SEO and last but not least in Section 6 concludes the correct knowledge of search engines and SEO tools and techniques.

\section{HOW SEARCH ENGINE WORKS?}

Obtaining the requested information from large databases (DB) of resources available on the web is the primary purpose of any search engine [11]. Search Engines are used as an essential tool for searching the necessary information on internet [12]. The location of where the data is stored on the internet does not matter. This is because Search Engines can retrieve the data from all around the web [13]. Due to userfriendly Search Engines, the usage of internet is increased tremendously in recent days. SEs carry out some activities in order to deliver the results to the users Figure 2 provides the detailed information on how search engine works? Based on SE working process, SEs are classified into four different categories [12, 14]: a) Crawler-based SE, b) Human-Powered Directories, c) Hybrid SE, d) Crawler-based SE. The differences between different categories of search engines are discussed in Table 1.

Table 1. Differences between Different Categories of Search Engines

\begin{tabular}{|c|c|c|c|}
\hline $\begin{array}{l}\text { Crawler-based search } \\
\text { engines (CBSE) }\end{array}$ & $\begin{array}{l}\text { Human-powered } \\
\text { directories (HPD) }\end{array}$ & Hybrid search engines & Other types of sarch engines \\
\hline $\begin{array}{l}\text { CBSE is a search engine that } \\
\text { goes out onto the internet to } \\
\text { find the information } \\
\text { requested by user [15]. }\end{array}$ & $\begin{array}{l}\text { HPDs are an internet } \\
\text { "database" of websites. }\end{array}$ & $\begin{array}{l}\text { Hybrid SEs are using both } \\
\text { the techniques, indexing } \\
\text { manually by humans and } \\
\text { crawler-based indexing }\end{array}$ & $\begin{array}{l}\text { Types of search engines that } \\
\text { uses other search engines to find } \\
\text { the results, for instance Meta } \\
\text { search engines. }\end{array}$ \\
\hline $\begin{array}{l}\text { It will find the latest } \\
\text { websites that have been } \\
\text { published to the internet. }\end{array}$ & $\begin{array}{l}\text { HDPs does not search the } \\
\text { Internet, it searches in its } \\
\text { own database of pre- } \\
\text { selected websites [16]. }\end{array}$ & $\begin{array}{l}\text { Hybrid SEs are using } \\
\text { crawlers as a primary and } \\
\text { manual listing as a } \\
\text { secondary mechanism [17]. }\end{array}$ & $\begin{array}{l}\text { This kind of search engine will } \\
\text { always show you which search } \\
\text { engines were used to find the } \\
\text { results. }\end{array}$ \\
\hline $\begin{array}{l}\text { None of the information it } \\
\text { finds has been looked at } \\
\text { before by anyone working } \\
\text { for the search engine. }\end{array}$ & $\begin{array}{l}\text { Websites are chosen } \\
\text { according to the subject of } \\
\text { the website. }\end{array}$ & $\begin{array}{l}\text { None of the information it finds } \\
\text { has been looked at before by } \\
\text { anyone working for the search } \\
\text { engine. }\end{array}$ & $\begin{array}{l}\text { None of the information } \\
\text { Metasearch engine finds has } \\
\text { been looked at before by anyone } \\
\text { working for the search engine } \\
\text { [18]. }\end{array}$ \\
\hline
\end{tabular}

\subsection{Crawler-Based Search Engines}

Crawler-based SEs are using the bot, spider or Crawler for crawling and indexing the new content to search DB., Every crawler-based SE is performing the four fundamental steps before showing any website in SERPs:

a. Crawling World Wide Web

b. Indexing web page contents

c. Calculating the relevancy

d. Retrieving the Result

Search Engines crawl the entire web to fetch the sites and web pages. A software known as a spider or a crawler is performing the crawling for Search Engine [1, 12, 19]. The frequency of the crawling entirely depends on SE. This is because the search engine may crawl after a few days or may take a few weeks. 
That is why sometimes the deleted or old page content can be seen in Search Engine Result Pages [12]. New content can only be seen in search results after SE crawl the web page again.

After crawling the web page indexing in the next step. The process of finding the expressions and words or terms which adequately describe the web page is known as indexing [20]. These words are called keywords, and the web page is allotted to these keywords [12]. Occasionally, when the meaning of a web page is not understandable for SE crawler, it ranks the web page lower on SERPs. In such case, there is a need to optimize the web page for SE crawlers to ensure page contents are easily understandable for crawlers [21]. Once SE crawlers pick up the right keywords, then it will assign the web page to these correct keywords and will also rank the web page high in SERPs [6]. SE compares the user's query with the web pages indexed in its database [12].

There is always a possibility that same search keyword occurs in more than one web page. Relevancy is critical in this case, so SE will start measuring the relevancy of all its indexed web pages with user's search query. Therefore, for calculating the relevancy, several algorithms are available [22]. For common factors like Meta tags, Keyword density or links all of these relevancy calculation algorithms got various relative weights. That is why for the same search query there will be different SEs that presenting the unique search results. All significant Search Engines are changing their algorithms periodically [8]. As a result, keeping a website at the top needs to adopt the latest changes.

The final step is retrieving the results. It consists of only displaying the search results in the browser; the search result pages are ordered from most relevant websites to the least related sites [23]. Most of the modern SEs are using the technique above to present the search results because these Search Engines are crawler-based [24]. The typical examples of Crawler-based SEs are Baidu, Yandex, Google, Bing, and Yahoo! [25].

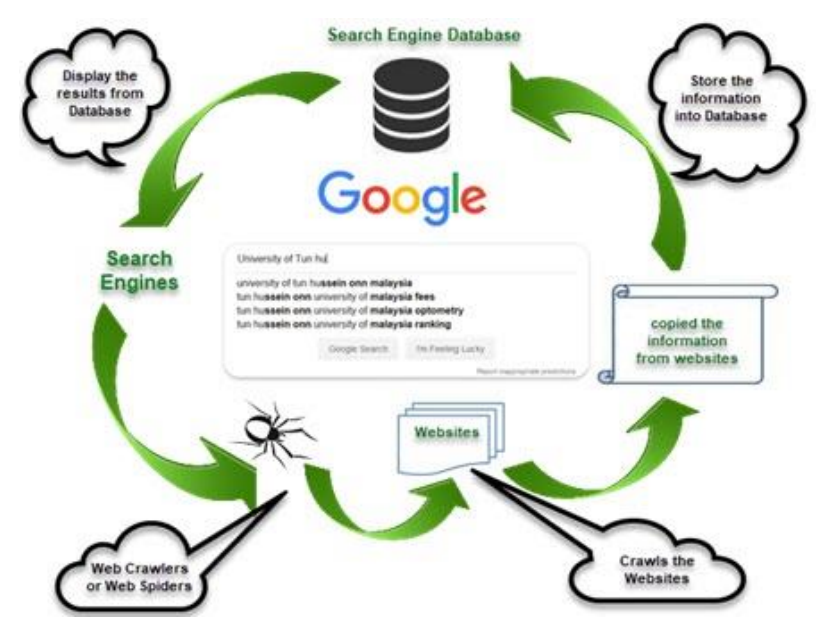

Figure 2. How search engine works?

\subsection{Human-Powered Directories}

Human-powered directories are also known as an open directory system. In these directories, humans are listing websites manually [26]. The process of the listing website in these directories is simple by following some required steps for listings. Owner of the website needs to submit site's URL, short description, keywords and the relevant category to human-powered directories [8, 12]. Administrators of these directories manually review the submitted website, they might add it to the appropriate category or can reject for directory listing. The relevancy of description of a website will be checked with the words entered in a search box. This means for a directory listing the description of a website is essential [26]. A great website with excellent content is more likely to be evaluated at no cost compared to the website with bad content.

\subsection{Hybrid Search Engines}

Hybrid SEs are using both the techniques, indexing manually by humans and crawler-based indexing for listing the websites in SERPs [8]. Google is using crawlers as a primary and manual listing as a secondary mechanism. Other crawler-based SEs are also using the same procedures for listings. When SE identify that a website is involved in spammy activities, then manual screening is required for including the site again in SERPs $[8,12]$. 


\subsection{Other Types of Sarch Engines}

Except above three main types of SEs, there are several other categories of SEs that are based on the usage [27]. There are different categories of SEs where some of them have many types of bots that only showing news, images, products, videos and local listings. The best example is Google News page, which can be used for searching news only from several newspapers around the world. The other categories of SEs like Dogpile are used to collect Meta data of the web page from other directories and SEs to present in the search results. These type of SEs are known as Metasearch Engines [22]. On particular area of semantic SEs like Swoogle they provide the correct search results by learning the contextual meaning of the search query.

\subsection{Search Engine Result Page}

A result page which is shown by the SE in reply to user's keyword is known as Search Engine Result Page [9]. The listing of results returned by SE in reply to the user's keyword is the primary component of the Search Engine Result Page [28]. However, the result's page may have some other contents such as paid advertisements. There are two common types of results returned by SE, which are (a) natural or organic results (Search Engine's algorithm retrieve these results in response to the user's keyword) and (b) paid or sponsored results such as advertisements [19]. Usually, the search results are ranked by relevance to the user's keyword. The organic result displayed on Search Engine Result Page typically consist of three things, a title, short description of the page and a link that point towards the original web page on the web. However, for sponsored or paid results, the sponsor decides what to show [28]. SE might display several Search Engine Result pages in response to user's query due to the vast number of relevant contents available on World Wide Web [22]. Usually, the Search Engine Result Page consist of ten results but the user's or SE preferences can limit the results per page. Every succeeding Search Engine Result Page will serve the lower relevancy results or a lower ranking [8].

\section{HOW SEARCH ENGINE OPTIMIZATION WORKS?}

The techniques used for increasing the website's ranking on SE is known as search engine optimization or SEO. Nowadays, small companies, big businesses, and platforms are using the SEO techniques for increasing their website's ranking and improving the visibility of their contents on the web [7]. This is because, by increasing the visibility of their contents among consumer's it can help them in gaining more popularity which results in more profitable business. Today SEO techniques very much revolve around the biggest search engine, Google. But the concept of SEO started with SE submission in the early time since SEs had limited crawling capabilities [29]. Eventually, it transformed into on-page search engine optimization; this technique makes sure that a web page is accessible to SEs and relevant to the targeted keywords. Since Google quickly becomes the dominant SE from 2000, so Google introduced the concept of PageRank, obtaining high-quality backlinks, it was the influential factor in the early days [30]. Due to the issue of link spamming, Google tweaked its ranking algorithm and started considering the contextual information of backlinks especially the anchor text. Researchers from Stanford University and Yahoo! introduced a similar kind of concept TrustRank, means a backlink is more valuable if it is coming from a trusted source [31]. Due to link exchanges, the context of the link becomes more critical, and Google started considering the deployment of the link on a web page and, and more importantly, the context of the website the link is on is of the highest importance. Furthermore, search engines also started considering the user signals such as bounce rates, click-through rates, and search patterns [32]. Finally, more advanced search engines like Google and Bing included real-time content and multimedia to match better user's needs. Table 2 discusses the more detailed history of search engine optimization.

Although the Search Engines are refining their webpage ranking algorithms continuously, there are two key factors that remain the foundation for high webpage ranking. Conceptually, there are two different methods for search engine optimization, which are (a) 0n-page SEO and (b) off-page SEO [2, 8].

Table 2. History of SEO: 1994-2018

\begin{tabular}{|c|c|c|c|c|c|}
\hline Year & \multicolumn{5}{|c|}{ Complete Timeline History of Search Engine Optimization } \\
\hline \multirow[t]{2}{*}{1994} & \multicolumn{3}{|l|}{ April 1994} & \multicolumn{2}{|l|}{ April 1994} \\
\hline & \multicolumn{3}{|c|}{$\begin{array}{l}\text { Yahoo! Directory was launched. Its dominance as a SE in years to come } \\
\text { will make SE submission a critical activity for SEOs [33]. }\end{array}$} & \multicolumn{2}{|c|}{$\begin{array}{l}\text { At the same time, for indexing the entire pages, } \\
\text { the first crawler (WebCrawler) was created [33]. }\end{array}$} \\
\hline \multirow[t]{2}{*}{1995} & February 1995 & August 1995 & September 1995 & September 1995 & December 1995 \\
\hline & $\begin{array}{l}\text { Infoseek was } \\
\text { launched, and it } \\
\text { becomes Netscape's } \\
\text { default SE [34]. }\end{array}$ & $\begin{array}{l}\text { Internet Explorer } \\
\text { was launched. It } \\
\text { started the first } \\
\text { "browser war" }\end{array}$ & $\begin{array}{l}\text { Hotbot and Looksmart were } \\
\text { launched [36]. }\end{array}$ & $\begin{array}{l}\text { Yahoo1 partners with } \\
\text { OpenText to provide } \\
\text { crawler-based search } \\
\text { results in addition to }\end{array}$ & $\begin{array}{l}\text { Altavista was launched } \\
\text { with an index that } \\
\text { dwarfs that of other SEs } \\
\text { and a powerful web }\end{array}$ \\
\hline
\end{tabular}


[35].

1997

In response to the dominance of on-page SEO, algorithm cracking software was developed that enabled SEOs to generate page 1 rankings at will [36].

1998 Early 1998

Several papers began to hint at the use of link citations in the SE algorithms of the future. GoTo, the world's first paid search platform was launched in February [37].

\section{October 1999}

Losing market share to Google, Altavista changed to an Internet portal and fades into uncertainty [39].

2000 June 2000

Yahoo! dropped Teoma, a search engine capable of evaluating the Altavista and used topic of a page was launched. Google AdWords Google search was also launched with a CPM Model [36] results instead [33].

2001 October 2001

Ask Jeeves acquired Teoma and used the Teoma algorithm to power its search engine [42].

2002 February 2002

After a disappointing start, AdWords was re-launched as a CPC platform, and rapidly cements itself as the premier paid search platform online [43].

2003 February 2003 Google acquired Blogger [45]. Same year WordPress was launched. These two services popularize blogging, and comment spam became a real problem for the search engines [46].

2004 February 2004

Yahoo! adopted its own algorithm based on Inktomi [33].

\section{January 2005}

The nofollow tag was created with joint support from Google, Yahoo, and MSN to combat blog comment spam. Later SEOs attempt to use the tag to optimize website architecture, with disputed success. This become known as "PageRank Sculpting" [30].

\section{February 2006}

Ask Jeeves was renamed as "Ask" [42]

2007 July 2007 Universal Search Google was launched by banned the Google [36].

September 2007
August 2002

Bob Massa created the first paid link network, the PR Ad Network, which brokers paid links between participating sites [44].

\section{September 2003}

In response to the increasing importance of anchor text, Patrick Gavin launched Text Link ads, making it easy for anyone to buy links across a wide range of sites in the TLA network [47].

July 2004

SEOs started talking about the "Google Sandbox." Digital Point Created the co-op network, a vast communal link farm designed to manipulate anchor text on a colossal scale [41].

February 2005

Microsoft rebranded MSN as In a continuing pattern of releasing major Live Search, with its own algorithm updates just before the holiday season, algorithm [36].

November 2006 September $2002 \quad$ October 2002

Many websites hosted Yahoo! acquires by Massa lose toolbar Inktomi, but continued PR, apparently as to use Google search punishment for the PR results, While MSN Ad Network. Massa continued to use Sued Google for this Inktomi as its engine loss but lost the case [33].

[44].

In an unprecedented move, Google made massive changes to its algorithm to combat spamdexing, wiping many legitimate websites from the SERPs at the same time. The update was known as "Florida" [41].

The search engines announced joint support for XML sitemaps [48].

Wikipedia became the host for 2 million articles. It demonstrated the importance of domain authority for years to come by ranking for almost everything [49]. 
Ads [36].

2008

2008

To provide help with keywords research, Google Suggest was launched.

2009

March $2009 \quad$ April $2009 \quad$ June 2009

Search engines Ask became Ask Microsoft dropped Live provided joint Jeeves again Search and released the support for the new [42]. Bing. Later, talked and canonical tag [41].

finalized with Yahoo! that will see Bing power the Yahoo! search results by the end of 2010 [50]. Google released Vince, commonly referred to as " The Brand Update," which shakes up the SERPs for top generic terms by looking at signals of user trust [41].

\begin{tabular}{|c|c|c|}
\hline July 2009 & & October 2009 \\
\hline Google & tested & Google and Microsoft \\
\hline "Caffeine," & & sign deals with Twitter \\
\hline infrastructure & $\begin{array}{l}\text { update } \\
\text { faster }\end{array}$ & $\begin{array}{l}\text { to gain access to Tweets } \\
\text { [41]. }\end{array}$ \\
\hline
\end{tabular}
indexing [41].

2010 December 2010

Two big search engines confirmed that social media networks Facebook and Twitter are affecting the SE ranking.

2011 February 2011

Google Panda Farmer was launched. It changed the results and ranking algorithm bought the high-quality web pages on top. Google panda punished web pages with thin and low-quality content. It forced SEO to concentrate on high-quality content [41].

2012 April 2012

Google Penguin was launched. It penalizes every web page that used shady backlink techniques [41].
June 2011

Schema.org was launched to promote, create and maintain structured data on the Internet. Microsoft, Google and Yahoo! announced the support for structured data [51].

2012

After launching the Google Penguin, it had a significant effect on all English language searches which was about $3.1 \%$ and around $3 \%$ on all other major languages, like German, Arabic, and Chinese.
2013 September 2013

The new update Hummingbird was launched by Google. This update affected $90 \%$ of entire searches and enabled Google to learn the meaning behind a search query. This update focused on the context of content versus single keyword match ups by comparing SE queries wisely [52].

\section{3}

Inbound marketing became "mainstream" and the focus became more on promotion and content, rather than traditional SEO best practices [53].

2014 October 2014

2014

Penguin 3.0 was released. It refreshed the web pages ranking and penalized the entire web pages which escaped their earlier updates [41].

2015 April 2015

Mobilegeddon was launched. It was designed to rank all those web pages higher which are mobile-friendly [54].
October 2015

RankBrain was launched. For delivering the smarter results to users Google introduced a new machine learning algorithm RankBrain [54].
2016 March 2016

Andrey Lipattsev the head of Google's search confirmed that the top 3 ranking factors of Google are content, RankBrain, and Links [55].
September 2016

Penguin 4.0 was launched. Now it was real-time and part of core algorithm.

2017 November 2017

New Meta Description limit was introduced which is 300 characters previously it was 155 characters [56].

2018 March 2018

The concept of Mobile-First indexing was introduced. Search engines started creating the search listings on the bases of the performance of the mobile version of a website [57].

\subsection{On-Page Search Engine Optimization}

On-page SEO deals with content and infrastructure of a website [6]. It includes an excellent selection of keywords, providing useful, knowledgeable and excellent content, inserting keywords in the 
appropriate places, and assigning the appropriate page titles to each page on a website [58]. It also targets the best keyword clusters and synchronizing the current content to target keyword clusters. Website architecture and infrastructure is considered best if the contents are created to target specific keywords clusters.

\subsection{Off-Page Search Engine Optimization}

On the other hand, Off-page SEO deals with how other online sources are referring a targeted website [6]. This technique deals with backlink building strategy which can be created using some different techniques like submitting the links to Search Engines, submitting the website's link to the open access web directories and discussion forums, creating open access pages, creating the business pages on social networks like Twitter, Google Plus, LinkedIn, Facebook, etc. Active social media presence plays a vital role in webpage ranking [58]. When Search Engine evaluates a webpage, it looks over two hundred different signals therefore Search Engines are refining their algorithm over four hundred times per year. So the best strategy for SEO is to keep changing the website with the changes in Search Engine's SEO algorithm [59].

\subsection{Search Engine Optimization Techniques}

In order to keep up with the latest technology, SEO are using three different types of techniques for Search Engine Optimization. These techniques are as follows [60]. The differences between White, Black and Gray Hat SEO, are discussed in Table 3.

Next section will discuss each of the techniques together with their advantages.

Table 3. Differeneces between White, Black and Gray Hat SEO

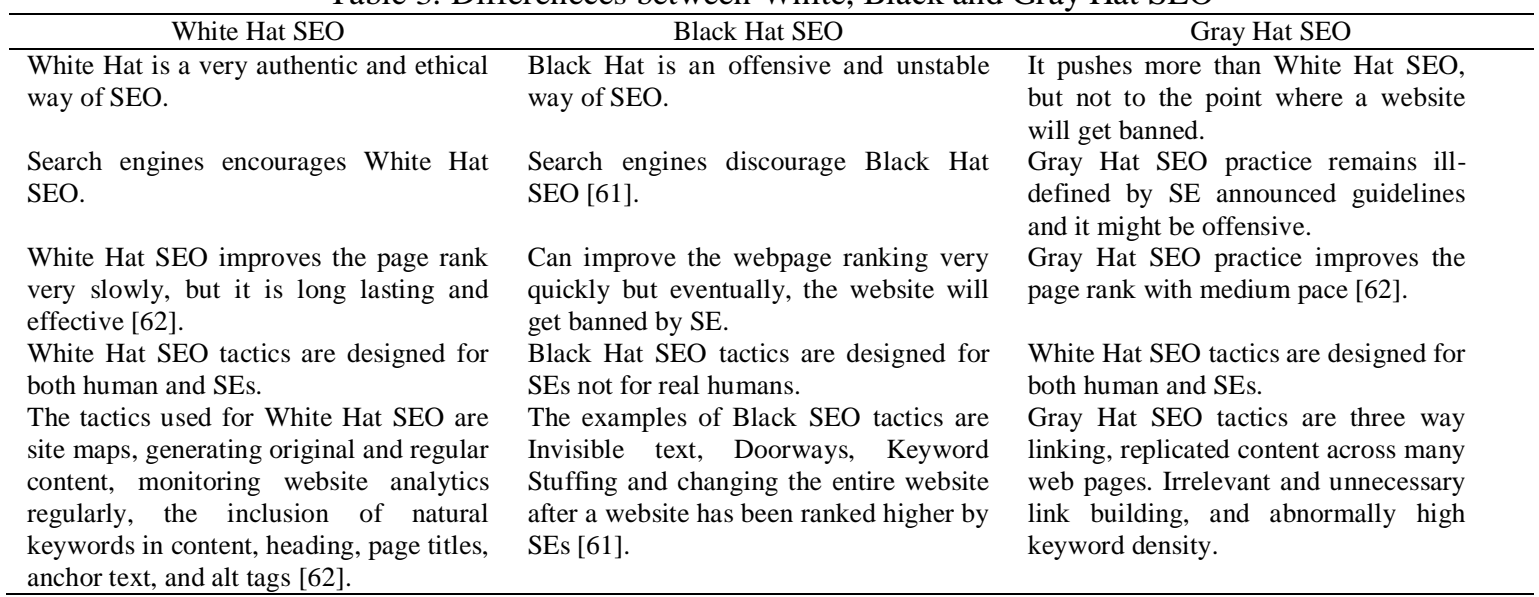

\subsubsection{White Hat Search Engine Optimization}

One of the most important and famous Search Engine Optimization technique is White Hate SEO. It is utilizing the right techniques and methods to increase the SE rankings of a webpage [6, 60]. White Hat SEO completely follows the rules and guidelines provided by Search Engines. Some of the methods used by What Hat SEO are the development of high-quality content, restructuring and optimization the content and code of a website, Keywords research and analysis, email marketing campaigns to opt-in customers and submitting the site-map to Search Engines [6]. Selecting White Hat SEO technique means slow and definitely will take some time but progressive and long-lasting growth in Search Engine Ranking.

\subsubsection{Black Hat Search Engine Optimization or Spamdexing}

On the other hand, Black Hat SEO is the illegal method of increasing the Search Engine ranking of a website [63]. It exploits the several weaknesses in the Search Engine ranking algorithm to obtain the high ranking for non-deserving websites. This SEO technique does not comply with Search Engine rules and guidelines especially Google. The wholesomeness level of Black Hat SEO is shallow due to the fact it uses the techniques like a hidden link, keyword stuffing, cloaking, Meta tag stuffing, hidden text and link spamming $[6,60,63]$. In addition, by using Black Hat SEO techniques means it is fast but short-lasting growth and unpredictable Search Engine ranking.

\subsubsection{Gray Hat Search Engine Optimization}

Gray Hat is a type of SEO technique which is neither white nor black. It does not entirely use the White Hat SEO technique and instead mixes both [24]. Gray Hat SEO is a transformation from White to 
Black and from Black to White. Usually, most of the companies are practicing the Gray Hat techniques to some extent for Search Engine Optimization due to the pressure from website owners to deliver excellent and quick results [64]. Moreover, they are not crossing the line to Black Hat SEO.

\section{TOOLS FOR SEARCH ENGINE OPTIMIZATION}

The strategies to improve SEO should be a continuous effort in order to improve webpage's natural search ranking and identify new techniques to design content to boost the business in a meaningful way. If a webpage is not monitored continuously then it means that letting the search ranking down [65]. Therefore, it is important to do the continuous monitoring on SEO tools. There are a number of proprietary and free SEO tools are available on the internet with the different type of uses and covering some common necessities [66]. Some of the tools are handy, easy to use and fast $[6,8,12]$. Some essential SEO tools are as below.

\subsection{Google Search Console}

Normally, the Google's Search Console previously known as Google Webmaster Tool is used for efficient management, better control, able to understand how Google is interacting with a webpage and getting essential data from Google about a webpage, webmasters. However, by using Google Search Console it will not help in identification of problems that can help a webpage performs best in search results instead it can help by the following means $[62,67]$.

a) In generating and analyzing the robots.txt file

b) In uploading Sitemap file in XML format

c) In specifying the preferred domain

d) In checking Googlebot crawling issues on a website

e) In removing the links previously crawled by Googlebot

f) In identification of issues with website description, title and Meta tags It can suggest HTML improvements.

\subsection{Bing Webmaster Tools}

Microsoft Bing search engine provides a free service to webmasters for adding their websites to index crawler. Initially, it was known as Bing Webmaster Center, but later they changed the name to Bing Webmaster Tools. Bing also provides several useful tools to webmasters for troubleshooting the indexing and crawling issues, analyzing website statistics, submission and ping tools, Sitemap creation, new content and community resources, and consolidation of content submission [68]. It includes the following features and tools to help webmasters for accessing the data and managing their websites on Bing Search Engine [69].

a) Crawl issues enable the webmasters to identify the potential problems with their websites, for instance, unsupported content-types, File Not Found (404), long dynamic URLs, and blocked by REP.

b) Backlink data enable the webmaster to obtain important data about their backlinks or referring links. Bing acquired part of this feature from Yahoo! Site Explorer [70].

c) Using Advanced filtering webmasters can scope the results quickly in website reports for zooming into the data they required.

d) For results analysis, webmasters can use Data Download which enables them to get first one thousand results in excel file.

e) The Keyword search tool enables them to search for new keywords for their website.

f) Robots.txt validator enables them to verify their robots.txt is meeting the standards.

g) Webmasters can use Markup validator to check if their website is meeting w3c standards.

h) To verify if the Bing search engine is viewing their sitemap accurately, they can use Bing Sitemaps.

i) Outbound links enable the webmasters to check the outbound links Bing search engine sees.

\subsection{BROWSEO}

It is a web application which shows how any Search Engine sees a website. Mostly all output purely focused on HTML, just like what Search Engines see when Search Engines are visiting a webpage. It disrobes a website down to a foundation level without images, fancy fonts, or headers and shows the vital Search Engine Optimization information. The used of BROWSEO in analyzing a website site can easily identified which specific part of a website needs improvement [71]. The relevancy of specific keyword and a page structure of a website can quickly be determined by switching between different features such as:

a) The number of internal and external links on a webpage.

b) Headings form $\mathrm{H} 1$ to $\mathrm{H} 6$.

c) A response code of server.

d) Meta information such as Meta description, title tag, and Meta robots. 
e) The total number of words on a webpage.

f) URL redirections and it types.

\subsection{Google analytics tool}

Once task on fixing and improving the indexing and crawling issues on a website been used using the Google webmaster tools. Then the next step is to monitor the incoming traffic on a website. Google Analytics is the right tool for monitoring and analyzing the incoming traffic [72]. It can show the indepth insight into [73]:

a) How a visitor behave and reach on the website

b) It helps in determining the various favorite content on website

c) It helps in measuring the impact of search engine optimization techniques applied to a website

Moreover, advanced users can access their server log files using Google Analytics which gives them more informative and thorough information about how users interact with the content of a website [74]. Another tool offered by Google is Google Website Optimizer. It enables the webmaster to conduct different experiments to identify what on-page changes can generate the excellent conversion rates with users [72]. The combination of Google Search Console, Google Website Optimizer, and Google Analytics is the efficient way to start improving the website.

\subsection{Screaming Frog}

Screaming Frog is also known as SEO Spider. It is a webpage crawler used to crawl URLs of websites' it fetches the vital on-page elements which helps in on-page Search Engine Optimization [75]. Screaming Frog is flexible, lite and it can crawl very quickly which allows analyzing a webpage's results in real-time. It helps the SEO experts and professionals to identify the Search Engine Optimization problems on a website quickly. It provides the detailed report at the end. SEO experts are using SEO Spider for identification of the following issues [76].

a) For finding the broken links on a website.

b) For analyzing the Metadata and page titles.

c) For discovering the duplicate contents on a webpage.

d) It can help in data extraction with XPath.

e) It can be used for review robots and directives.

f) Can be used to generate XML sitemap.

g) For integration with Google Analytics.

h) Helpful in audit redirects.

\subsection{GTMetrix}

GTMetrix is a useful web application for analyzing the load time of a website. It can quickly identify the content and pages that takes a long time to come up [77]. Website speed plays a significant role in Search Engine rankings therefore it will slow webpage speed.GTMetrix is an excellent tool for examining the load speed of a webpage where it can diagnose the issues and problems, and it also suggests the possibilities for improvement by applying which website that can be polished further. There are many other tools that are available for checking the page-speed, but GTMetrix is most favorite as compare to others due to its thoroughness and user-friendliness [77]. The other page-speed tools which might be helpful are Google PageSpeed Insights and Pingdom. User can enter the URL of a website in these web applications, and these applications will come up with the webpage speed score and a list of suggestions to improve it. E.g., it can suggest that combine multiple CSS files into a single file or compress the code to improve the load times.

\subsection{Rank Checker}

It is used to check how a website is performing in search and where it lands in search engine result pages. Rank Checker monitors the ranking of a website in search results and provides the tips to improve ranking further [78]. Though moving a website up in search ranking is a time consuming process, but Rank Checker can be installed in the toolbar for monitoring the website continuously.

\subsection{Google Trends}

Google provides another very excellent tool that is known as Google Trends where it shows the statistics about the amount of keywords searches over different time spans can be viewed using Google Trends [79]. Moreover, keywords searches data is available since 2004. Furthermore, by using Google Trends data it can be partitioned by region and language to plot various key phrases on a single graph. Therefore, webmasters are using Google Trends to anticipate traffic for a specific period [79]. 


\subsection{Google AdWords}

Google AdWords is used for purchasing the ads on Google's SERPs [80]. These ads will appear in the sponsored links section on top of Google Search Engine Result Pages. It is important to know that these ads will appear solely on searches performed on Google Search Engine's home page, not in the results of other Engines like Yahoo! Alternatively, Google-affiliated sites [80]. Some significant advantages of Google AdWords are as below [81]:

Ads will run immediately after submission no need to wait for listing on Google. Changes can be made at any time to the ads, by tweaking the advertisement and keywords selection the advertiser can get best results.

It contains the keyword research tool which can be used to find the keywords for an AdWords campaign. For example, if the advertiser is running an online digital consulting services, the keywords research tool can efficiently recommend related keywords like "Proofreading" or "Social Media Strategy." In addition, by adding alternative terms it can help in finding new consumers that might otherwise have missed [80].

\subsection{Responsive Design Test}

It is imperative to check how a website looks on different devices like laptop, tablet, phablet, and smartphone. Moreover, search Engines assign the higher search ranking to a website that looks excellent on all these devices, no matter their orientation or size [82]. Therefore, in order to make sure that a website looks perfect on every device, web designers are using responsive website design. The responsive website looks great on every device, so no need to develop multiple websites for different devices [82]. Furthermore, design test can be used to check if a website has a responsive design or not a responsive.

\subsection{Wayback Machine}

The Wayback Machine enables the users and owners of the websites to check the archived versions of websites across the time [83]. It contains the comprehensive and authentic record of the internet. It can be seen on Wayback Machine that shows how a website looks in the past. It can be used as an excellent investigation tool, for example, the owner of a website is noticing odd changes in traffic after updating the website, and the previous site-backup is not available [83, 84].

\subsection{Keywordtool.io}

It is a freemium SaaS product which uses several Search Engines and Google Autocomplete to produce the related and relevant keywords for any article. Keywordtool.io is quick and straightforward to use to get many keyword ideas [85]. The excellent feature of this SaaS product is that it can be utilized for YouTube, Amazon, Google, App Store and Bing keywords. It is particularly beneficial for long-tail keywords those cannot be obtained using Google Keyword Planner, due to low search volume [86].

\subsection{Moz}

It is consider as a complete and user-friendly suite of inbound marketing tools. It has several tools in its Search Engine Optimization Toolbox including [87]:

a) Keywords Explorer, it is a keyword research tool which provides Search Engine Optimization Competition, Keyword Suggestions, Search Engine Result Page features, actual search volume data, opportunity and saved lists.

b) MozPro is used for website SEO checkups; it provides competitor tracking, Search Engine Optimization fixes, Search Engine Result Page feature tracking, and rank tracking.

c) To get the link data, Open Site Explorer can be used.

d) MozRank is similar to Google PageRank for calculating the PageRank of a webpage.

e) Moz also got the tool for researching popular search trends.

f) MozBar is user-friendly SEO tool for the browser.

\subsection{Google Recommendations}

In addition, Google also provides some fundamental guidelines which can improve the webpage's ranking and making the webpage more optimized [88]. These guidelines are as below:

a) A webpage can directly be submitted to Google Search Engine using the link http://www.google.com/addurl.html

b) A webmaster can submit the webpage and XML sitemap using Google Search Console. Google will use the XML sitemap to discover the structure of the website and will increase the coverage of web pages.

c) A webmaster should avoid the Black Hat SEO techniques like cloaking, hidden text or link, scraped content, automatically generated content, doorway pages, populating pages with irrelevant keywords, 
automated queries submission to Google, sneaky redirects, building web pages with malicious behavior such as installing viruses or phishing, etc.

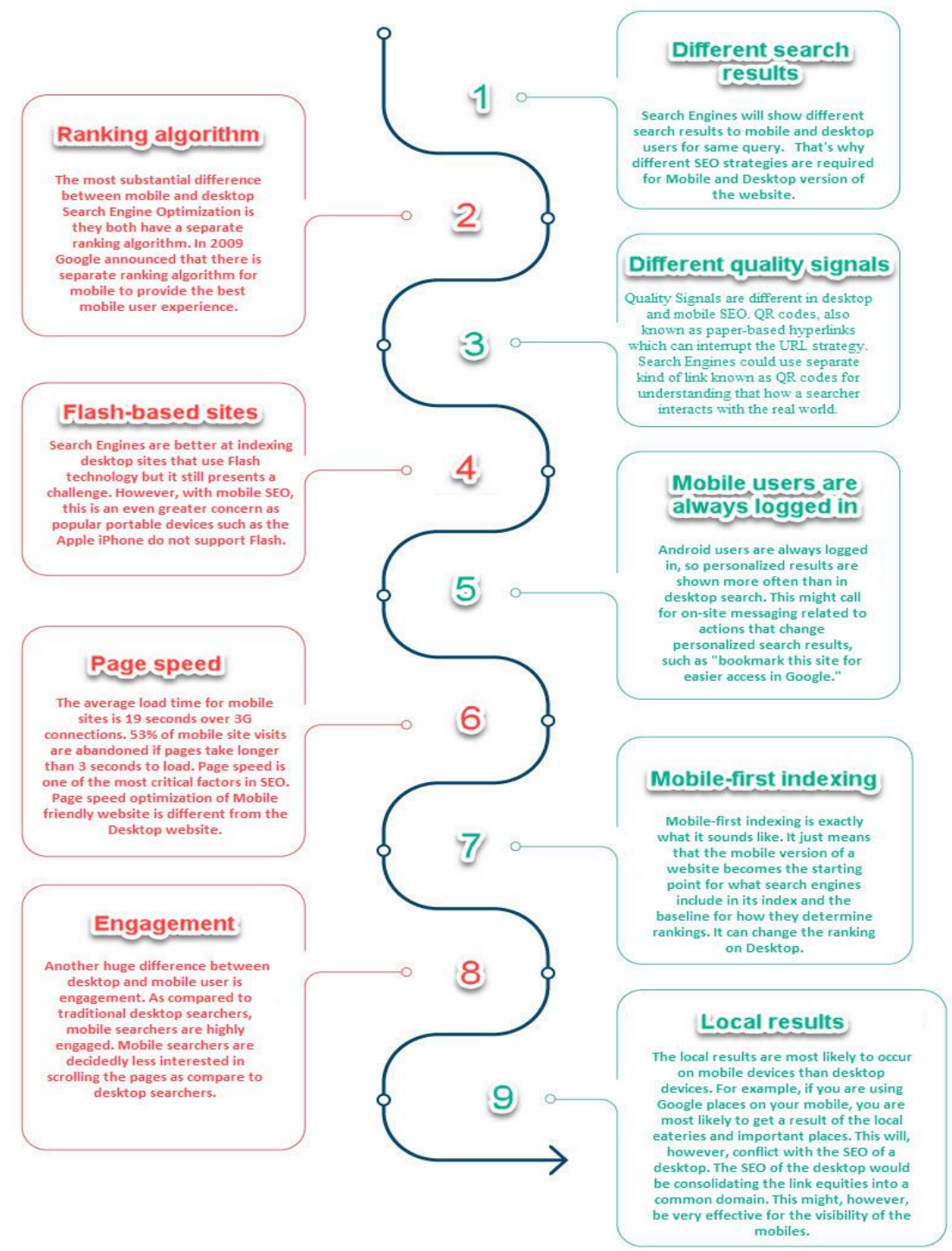

Figure 3. Difference between mobile and desktop search engine optimization

\section{MOBILE VS. DESKTOP SEARCH ENGINE OPTIMIZATION}

Nowadays in internet marketing field, the importance of Search Engine Optimization is getting popular. However, the desktop or traditional Search Engine Optimization is very essential, but the website also needs to be optimized for mobile SEO [9]. Some thoughts saying that all the techniques of desktop or traditional Search Engine Optimization currently in use will also work on mobile Search Engine Optimization is not true. Mainly because both of these are two separate and different entities, so these should be treated separately. Mobile Search Engine Optimization is an exceptional type of SEO [8]. In addition, optimizing a website for mobile searches is different from traditional or desktop SEO in four different ways [89]. Figure 3 discusses the difference between mobile and desktop SEO in detail.

\subsection{Search Behavior}

Search behavior is one of the critical difference between desktop and mobile users. Usually, all the mobile users are not searching the web with keywords. They might use Voice Search, Google Goggles, Gesture Search and some other mobile-first modes searching techniques, for a mobile user it is not necessary to always type a keyword in Google Search screen anymore [8]. Moreover, sometimes mobile searcher uses the same keyword, but the meaning is different (e.g., a phone scanned coupon vs. printed out coupon), and 
sometimes they might use the various keywords altogether. A research study conducted by Google also indicates that mobile users are searching in different contexts at different times than traditional searchers on the desktop, which completely changes their search intent [89].

\subsection{Ranking Algorithm}

The most substantial difference between mobile and desktop Search Engine Optimization is they both have a separate ranking algorithm. In 2009 Google announced that there is separate ranking algorithm for mobile to provide the best mobile user experience. The idea of Google behind the separate ranking algorithm is to provide the same user experience to mobile users as they are providing to the desktop users $[8,9]$. One of the significant differences between mobile and desktop ranking algorithm is the location that changes the search results for desktop vs. mobile searchers.

\subsection{Engagement}

Another huge difference between desktop and mobile user is engagement. As compared to traditional desktop searchers, mobile searchers are highly engaged. Mobile searchers are decidedly less interested in scrolling the pages as compare to desktop searchers [9]. Mobile users are always on the go; they want their information quickly. Occasionally they dig through Search Engine Result Pages to find their relevant information. Therefore, being on top of mobile Search Engine Result pages is desirable in mobile SEO more than desktop SEO [9].

\subsection{Different Quality Signals}

Finally, Quality Signals are different in desktop and mobile SEO. QR codes, also known as paperbased hyperlinks which can interrupt the URL strategy. Search Engines could use separate kind of link known as QR codes for understanding that how a searcher interacts with the real world and to bring more appropriate content when user search for it. However, it is not the only kind of signals Search Engines are using for making an excellent mobile search experience [90].

\section{CONCLUSION}

In the present era of the World Wide Web, Search Engine is a handy tool. There are several types of web Search Engines are available in the market, but the most famous is Google Search Engine. In all three types of Search Engine Optimization techniques, the White Hat SEO is safest and long-lasting. In addition, White Hat Search Engine Optimization techniques is best for securing the top ranking on Search Engine Result Pages. Both the on-page and off-page Search Engine Optimization techniques are essential for excellent search results. The process includes a SE spider downloading a webpage and saving it on the server of Search Engine, where indexer extracts the several necessary information about the webpage, e.g., words on a webpage, the location of words, weight for particular words and, incoming and outgoing links on the webpage. For crawling later, all these are placed in a scheduler. Owners of the websites and SEO professionals already recognized the importance of high web ranking and visibility of their contents on Search Engine Result Pages, therefore for achieving the excellent results in minimum time they started to use of Search Engine Optimization Tools. SEO tools are best for keeping an eye on the website for SEO related issues.

\section{ACKNOWLEDGEMENTS}

This work is sponsored by Telkom University, Bandung Indonesia under its publication scheme.

\section{REFERENCES}

[1] D. Sullivan, "How search engines work," SEARCH ENGINE Watch. http//www. searchenginewatch. com/webmasters/work. html (last Updat. June 26, 2001)(on file with New York Univ. J. Legis. Public Policy), 2002.

[2] E. Convey, "Porn sneaks way back on web," Bost. Her., vol. 28, 1996.

[3] T. Seymour, D. Frantsvog, and S. Kumar, "History of search engines," Int. J. Manag. Inf. Syst., vol. 15, no. 4, pp. 47, 2011.

[4] S. Robertson, “A Brief History of Search Results Ranking,” IEEE Ann. Hist. Comput., 2019.

[5] J. Lobo, "The history of the search engine: from index cards to the AI chatbot." [Online]. Available: https://www.inbenta.com/en/blog/history-search-engine/. [Accessed: 04-Apr-2019].

[6] A. Shahzad et al., "The Impact of Search Engine Optimization on The Visibility of Research Paper and Citations," JOIV Int. J. Informatics Vis., vol. 1, no. 4-2, pp. 195-198, 2017.

[7] D. Giomelakis and A. A. Veglis, "Search Engine Optimization," in Advanced Methodologies and Technologies in 
Network Architecture, Mobile Computing, and Data Analytics, IGI Global, 2019, pp. 1789-1800.

[8] J. L. Ledford, Search engine optimization bible, vol. 584. John Wiley \& Sons, 2015.

[9] L. S. Park, J. Yu, S. Yu, and L. Liao, "Search engine optimization for category specific search results." Google Patents, 25-Aug-2015.

[10] M. R. Baye, B. De los Santos, and M. R. Wildenbeest, "Search engine optimization: what drives organic traffic to retail sites?," J. Econ. Manag. Strateg., vol. 25, no. 1, pp. 6-31, 2016.

[11] A. Althaf Ali and R. M. Shafi, "Test-retrieval framework: performance profiling and testing web search engine on non factoid queries," Indones. J. Electr. Eng. Comput. Sci., vol. 14, no. 3, pp. 1373-1381, 2019.

[12] A. Halavais, Search engine society. John Wiley \& Sons, 2017.

[13] U. Gajendragadkar and S. Joshi, "Context Sensitive Search String Composition Algorithm using User Intention to Handle Ambiguous Keywords,” Int. J. Electr. Comput. Eng., vol. 7, no. 1, p. 432, 2017.

[14] E. A. Green, K. L. Markey, and M. Kreider, "Subject matter context search engine." Google Patents, 12-Apr-2016.

[15] J. Liu, S. K. Nath, J. D. Padhye, and L. R. Sivalingam, "Deep application crawling." Google Patents, 21-Aug-2018.

[16] R. S. Bhandari and A. Bansal, "Impact of Search Engine Optimization as a Marketing Tool," Jindal J. Bus. Res., vol. 7, no. 1, pp. 23-36, 2018.

[17] J. Zhang, X. Cai, T. Le, W. Fei, and F. Ma, "A Study on Effective Measurement of Search Results from Search Engines," J. Glob. Inf. Manag., vol. 27, no. 1, pp. 196-221, 2019.

[18] D. AnitaKumari and J. Thakur, "Semantic Web Search Engines: A Comparative Survey," 2019.

[19] M. Moran and B. Hunt, Search engine marketing, Inc.: Driving search traffic to your company's website. IBM Press, 2014.

[20] R. Bodenheim, J. Butts, S. Dunlap, and B. Mullins, "Evaluation of the ability of the Shodan search engine to identify Internet-facing industrial control devices," Int. J. Crit. Infrastruct. Prot., vol. 7, no. 2, pp. 114-123, 2014.

[21] T. Joachims, L. Granka, B. Pan, H. Hembrooke, and G. Gay, "Accurately interpreting clickthrough data as implicit feedback," in ACM SIGIR Forum, 2017, vol. 51, no. 1, pp. 4-11.

[22] S. Büttcher, C. L. A. Clarke, and G. V Cormack, Information retrieval: Implementing and evaluating search engines. Mit Press, 2016.

[23] V. Boppana and S. P, "Focused crawling from the basic approach to context aware notification architecture," Indones. J. Electr. Eng. Comput. Sci., vol. 13, no. 2, p. 492, Feb. 2019.

[24] J. Teevan, S. T. Dumais, and E. Horvitz, "Personalizing search via automated analysis of interests and activities," in Proceedings of the 28th annual international ACM SIGIR conference on Research and development in information retrieval, 2005, pp. 449-456.

[25] T. V Udapure, R. D. Kale, and R. C. Dharmik, "Study of web crawler and its different types," IOSR J. Comput. Eng., vol. 16, no. 1, pp. 1-5, 2014.

[26] G. C.-H. Yang, "Method and system for user and reference ranking in a database." Google Patents, 09-Jun-2015.

[27] M. De Choudhury, M. R. Morris, and R. W. White, "Seeking and sharing health information online: comparing search engines and social media," in Proceedings of the 32nd annual ACM conference on Human factors in computing systems, 2014, pp. 1365-1376.

[28] K. Jerath, L. Ma, and Y.-H. Park, "Consumer click behavior at a search engine: The role of keyword popularity," $J$. Mark. Res., vol. 51, no. 4, pp. 480-486, 2014.

[29] M. J. Bordash and L. S. Deluca, "Search engine optimization based upon most popular search history." Google Patents, 02-Jan-2018.

[30] D. F. Gleich, "PageRank beyond the Web," SIAM Rev., vol. 57, no. 3, pp. 321-363, 2015.

[31] J. J. Whang, Y. S. Jeong, I. S. Dhillon, S. Kang, and J. Lee, "Fast Asynchronous Anti-TrustRank for Web Spam Detection," 2018.

[32] T. Mavridis and A. L. Symeonidis, "Identifying valid search engine ranking factors in a Web 2.0 and Web 3.0 context for building efficient SEO mechanisms," Eng. Appl. Artif. Intell., vol. 41, pp. 75-91, 2015.

[33] V. P. Rindova, L. L. Martins, and A. Yeow, "The hare and the fast tortoise: Dynamic resource reconfiguration and the pursuit of new growth opportunities by Yahoo and Google (1995-2007)," in Resource Redeployment and Corporate Strategy, Emerald Group Publishing Limited, 2016, pp. 253-284.

[34] B. McCullough, How the Internet Happened: From Netscape to the IPhone. Liveright Publishing, 2018.

[35] M. Aiello, "The Browser Lament," in The Web Was Done by Amateurs, Springer, 2018, pp. 51-61.

[36] G. Sharma, S. Sharma, and H. Singla, "Evolution of web crawler its challenges," Int. J. Comput. Technol. Appl., no. 9 , p. $11,2016$.

[37] C. A. Wilkens, R. Cavallo, and R. Niazadeh, "GSP: the cinderella of mechanism design," in Proceedings of the 26th International Conference on World Wide Web, 2017, pp. 25-32.

[38] A. Halavais, "How Search Shaped and Was Shaped by the Web," SAGE Handb. Web Hist., p. 242, 2018.

[39] S. A. Ganaie and M. Khazer, "Diversity of Information Sources in the Digital Age: An Overview," J. Adv. Libr. Sci., vol. 2, no. 2, pp. 53-61, 2018.

[40] "Search Engine Strategies | Revolvy." [Online]. Available: https://www.revolvy.com/page/Search-EngineStrategies?smv=1485358. [Accessed: 08-Apr-2019].

[41] A. Chandra, M. Suaib, and R. Beg, "Google Search Algorithm updates against web spam,” Dep. Comput. Sci. Eng. Integr. Univ., pp. 1-10.

[42] A. Plaza, J. A. Benediktsson, J. Li, T. Yang, and B. Zhang, "Spatial Technology and Social Media [Scanning the Issue]," Proc. IEEE, vol. 105, no. 10, pp. 1851-1854, 2017.

[43] K.-I. Voigt, O. Buliga, and K. Michl, "Beyond the search engine: the case of Google," in Business Model Pioneers, Springer, 2017, pp. 81-94. 
[44] “SEO Blog.” [Online]. Available: http://www.seobook.com/archives/cat_links.shtml. [Accessed: 08-Mar-2019].

[45] A. Bruns, "Blog," Wiley-Blackwell Encycl. Soc. Theory, pp. 1-3, 2017.

[46] L.-J. Filotrani, WordPress for Journalists: From Plugins to Commercialisation. Routledge, 2018.

[47] Z. Bezovski, "The Historical Development of Search Engine Optimization," in Information and Knowledge Management, 2015, vol. 5, no. 15, pp. 91-96.

[48] A. Polleres, M. R. Kamdar, J. D. Fernandez Garcia, T. Tudorache, and M. A. Musen, "A more decentralized vision for linked data," 2018.

[49] M. Proffitt, Leveraging Wikipedia: Connecting Communities of Knowledge. American Library Association, 2018.

[50] H. Zhang, A. Jain, G. Khandelwal, C. Kaushik, S. Ge, and W. Hu, "Bing developer assistant: improving developer productivity by recommending sample code," in Proceedings of the 2016 24th ACM SIGSOFT International Symposium on Foundations of Software Engineering, 2016, pp. 956-961.

[51] R. V Guha, D. Brickley, and S. Macbeth, "Schema. org: evolution of structured data on the web," Commun. ACM, vol. 59, no. 2, pp. 44-51, 2016.

[52] S. N. Nayak, "Google Products for Enhancing Library Services," Asian J. Inf. Sci. Technol., vol. 7, no. 2, pp. 4752, 2017.

[53] "The History of SEO : Brussels' eMarketing Blog (SEO)." [Online]. Available: http://brussels.emarketingservices.eu/2010/06/21/the-history-of-seo/. [Accessed: 06-Mar-2019].

[54] P. Nanda, S. Patnaik, and S. Patnaik, "Towards Algorithmic Business: A Paradigm Shift in Digital Business," in Digital Business, Springer, 2019, pp. 3-22.

[55] C. Rovira, F. Guerrero-Solé, and L. Codina, "Received citations as a main SEO factor of Google Scholar results ranking," El Prof. la Inf., vol. 27, no. 3, pp. 559-569, 2018.

[56] "Meta descriptions are going to be shorter again - Yoast." [Online]. Available: https://yoast.com/shorter-metadescriptions/. [Accessed: 02-Feb-2019].

[57] M. Mashrafi, "Investigate the effect of semantic search on search engine opti-mization." Cardiff Metropolitan University, 2017.

[58] D. Dover and E. Dafforn, Search engine optimization (SEO) secrets. Wiley publishing, 2011.

[59] C. O. Y. Lin and R. Yazdanifard, "How Google's New Algorithm, Hummingbird, Promotes Content and Inbound Marketing," Am. J. Ind. Bus. Manag., vol. 04, no. 01, pp. 51-57, 2014.

[60] K. Svore and C. Burges, "Web spam page classification using query-dependent data." Google Patents, 14-Dec2010.

[61] R. D. Gaharwar and D. B. Shah, "Blackhat Search Engine Optimization Techniques (SEO) and Counter Measures," 2018.

[62] V. N. Gudivada, D. Rao, and J. Paris, "Understanding search-engine optimization," Computer (Long. Beach. Calif)., vol. 48, no. 10, pp. 43-52, 2015.

[63] A. Ntoulas, M. Najork, M. Manasse, and D. Fetterly, "Detecting spam web pages through content analysis," Proc. 15th Int. Conf. World Wide Web - WWW '06, p. 83, 2006.

[64] A. Taweesiriwate, B. Manaskasemsak, and A. Rungsawang, "Web spam detection using link-based ant colony optimization," in 2012 IEEE 26th International Conference on Advanced Information Networking and Applications, 2012, pp. 868-873.

[65] S. Kim, H. Park, and G. Lebanon, "Fast Spammer Detection Using Structural Rank," pp. 1-8, 2014.

[66] M. Cui and S. Hu, "Search engine optimization research for website promotion," Proc. - 2011 Int. Conf. Inf. Technol. Comput. Eng. Manag. Sci. ICM 2011, vol. 4, pp. 100-103, 2011.

[67] “About Search Console." [Online]. Available: https://support.google.com/webmasters/answer/9128668?hl=en. [Accessed: 04-Feb-2019].

[68] "Bing Webmaster Tools Help \& How-To Center," 2554. [Online]. Available: https://www.bing.com/webmaster/help/help-center-661b2d18. [Accessed: 04-Apr-2019].

[69] J. E. Lincoln, "The Ultimate Guide To Bing Webmaster Tools." [Online]. Available: https://searchengineland.com/ultimate-guide-bing-webmaster-tools-221206. [Accessed: 04-Apr-2014].

[70] V. Fox, "Bing Revamps Their Webmaster Tools \& Launches Partial Yahoo Site Explorer Replacement.” [Online]. Available: https://searchengineland.com/bing-revamps-their-webmaster-tools-and-launches-partial-yahoo-siteexplorer-replacement-123466. [Accessed: 04-Apr-2019].

[71] “Your New SEO Browser.” [Online]. Available: http://www.browseo.net/. [Accessed: 04-Feb-2019].

[72] B. Clifton, Advanced web metrics with Google Analytics. John Wiley \& Sons, 2012.

[73] B. Plaza, "Google Analytics for measuring website performance," Tour. Manag., vol. 32, no. 3, pp. 477-481, 2011.

[74] Google, "Google Analytics for Beginners - Behavior reports," 2018. [Online]. Available: https://analytics.google.com/analytics/academy/course/6/unit/3/lesson/3. [Accessed: 04-Feb-2019].

[75] G. Le Breton, N. Bergeron, and S. Hallé, "A Reference Framework for the Automated Exploration of Web Applications," in 2014 19th International Conference on Engineering of Complex Computer Systems, 2014, pp. 81-90.

[76] “Screaming Frog SEO Spider." [Online]. Available: https://www.screamingfrog.co.uk/seo-spider/. [Accessed: 17Jan-2019].

[77] A. Shenoy and A. Prabhu, "SEO Hub: Utilities and Toolsets," in Introducing SEO, Springer, 2016, pp. $103-117$.

[78] P. R. Checker, "Google Page Rank Checker." 2014.

[79] H. Choi and H. Varian, "Predicting the present with Google Trends," Econ. Rec., vol. 88, pp. 2-9, 2012.

[80] B. Geddes, Advanced Google AdWords. John Wiley \& Sons, 2014. 
[81] C. Antoun, C. Zhang, F. G. Conrad, and M. F. Schober, "Comparisons of online recruitment strategies for convenience samples: Craigslist, Google AdWords, Facebook, and Amazon Mechanical Turk," Field methods, vol. 28, no. 3, pp. 231-246, 2016.

[82] S. Mohorovičić, "Implementing responsive web design for enhanced web presence," in 2013 36th International Convention on Information and Communication Technology, Electronics and Microelectronics (MIPRO), 2013, pp. $1206-1210$.

[83] J. Murphy, N. H. Hashim, and P. O'Connor, "Take me back: validating the Wayback Machine," J. Comput. Commun., vol. 13, no. 1, pp. 60-75, 2007.

[84] S. Hackett, B. Parmanto, and X. Zeng, "A retrospective look at website accessibility over time," Behav. Inf. Technol., vol. 24, no. 6, pp. 407-417, 2005.

[85] A. Shenoy and A. Prabhu, "Keyword Research and Strategy," in Introducing SEO, Springer, 2016, pp. 73-84.

[86] M. S. A. EBRAHIM, "Marketing manager, role development and operations," 2017.

[87] R. Fishkin and T. Høgenhaven, Inbound marketing and SEO: Insights from the Moz Blog. John Wiley \& Sons, 2013.

[88] "Search Engine Optimization (SEO) Starter Guide." [Online]. Available: https://support.google.com/webmasters/answer/7451184?hl=en. [Accessed: 05-Jan-2019].

[89] J. Grappone, Search engine optimization: an hour a day. John Wiley \& Sons, 2011.

[90] M. P. Evans, "Analysing Google rankings through search engine optimization data," Internet Res., vol. 17, no. 1, pp. 21-37, 2007.

\section{BIOGRAPHIES OF AUTHORS}

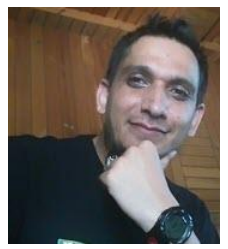

Asim Shahzad doing his $\mathrm{PhD}$ in IT from Faculty of Computer Science and Information Technology (FSKTM), Universiti Tun Hussein Onn Malaysia (UTHM). He received M.Phil. degree in Computer Science Specialization in Information Retrieval Systems in 2009 from The Quaid e Azam University Islamabad, Pakistan. He received his BS degree in Computer Science from Hazara University, Mansehra, Pakistan, in 2006. His research interests include Web Spam Detection, Search Engine Optimization, Information Retrieval, Data mining, and Text mining.

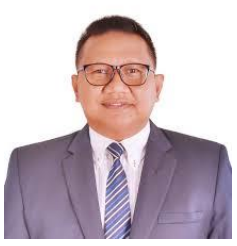

Deden Witarsyah Jacob received an M.Eng degree from Curtin University of Technology, Australia, in 2006 and Ph.D in 2018 from University Tun Hussein Onn Malaysia. He is the Head of the Open Data Research Center of Industrial Engineering Faculty and Senior Lecturer in the Information System Department of Telkom University, Indonesia. His main research interests include e-government, information technology master planning, e-services, decision-making models, decision support system, and information system project management.

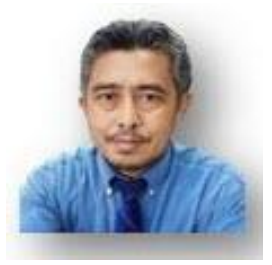

Nazri Mohd Nawi received his B.S. degree in Computer Science from University of Science Malaysia (USM), Penang, Malaysia. His M.Sc. degree in computer science was received from University of Technology Malaysia (UTM), Skudai, Johor, Malaysia. He received his Ph.D. degree in Mechanical Engineering department, Swansea University, Wales Swansea. He is currently a lecturer in Software Engineering Department at Universiti Tun Hussein Onn Malaysia (UTHM). His research interests are in optimization, data mining techniques and neural networks.

Hairulnizam Mahdin is an Associate Professor at Department of Information Security and Web,

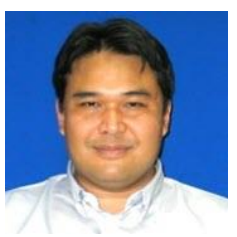
Faculty of Computer Science and Information Technology, Universiti Tun Hussein Onn Malaysia. He completed his Ph.D. thesis in 2012 and was conferred a doctorate degree from Deakin University Australia in the same year. His research focuses on the area of data management, IoT, RFID, information security, software engineering and web technology. He has published his research in both ISI and Scopus-indexed journals. He currently supervises five Ph.D. students and one Master's student.

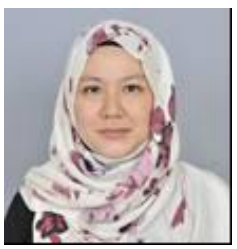

Marheni Eka Saputri is a lecturer, business owner and Small Medium Enterprise (SME) Consultant. She received an M.B.A degree from Gadjah Mada University, Bandung in 2011. She is senior lecturer in the Business Administration Department of Telkom University. Her main research interest include digital marketing, consumer behavior, ritel management and marketing communication. 